\title{
Lidil
}

Revue de linguistique et de didactique des langues

49 | 2014

L'analyse des données didactiques

\section{Éliane Viennot, Non, le masculin ne l'emporte pas sur le féminin! Petite histoire des résistances de la langue française}

Donnemarie-Dontilly, Éditions iXe, 2014

\section{Marielle Rispail}

\section{OpenEdition}

\section{Journals}

Édition électronique

URL : http://journals.openedition.org/lidil/3530

DOI : $10.4000 /$ lidil.3530

ISSN : $1960-6052$

Éditeur

UGA Éditions/Université Grenoble Alpes

Édition imprimée

Date de publication : 25 mai 2014

Pagination : 201-202

ISBN : 978-2-84310-272-1

ISSN : $1146-6480$

\section{Référence électronique}

Marielle Rispail, «Éliane Viennot, Non, le masculin ne l'emporte pas sur le féminin! Petite histoire des résistances de la langue française », Lidil [En ligne], 49 | 2014, mis en ligne le 25 novembre 2015, consulté le 22 septembre 2020. URL : http://journals.openedition.org/lidil/3530 ; DOI : https://doi.org/ 10.4000/lidil.3530 


\section{Éliane Viennot, Non, le masculin ne l'emporte pas sur le féminin! Petite histoire des résistances de la langue française, Donnemarie- Dontilly, Éditions iXe, 2014}

Dans les 120 pages de cet opuscule, aussi réjouissant qu'érudit, Éliane Viennot ${ }^{1}$, qui a déjà publié chez cette courageuse petite maison d'édition, vient pourfendre avec vigueur quelques idées reçues sur la langue française et nous démontre quelques «vérités» bien senties.

La première est que les «règles» que nous respectons et enseignons n'ont pas existé de toute éternité et qu'elles ont même fait l'objet de débats.

La deuxième est que l'établissement desdites règles a souvent obéi à des mobiles qui étaient tout sauf linguistiques et scientifiques.

La troisième est que, subséquemment, ces mêmes règles peuvent encore évoluer, puisqu'il n'y a pas de fatalité linguistique, si tant est que nous nous intéressions à la question...

C'est à la place du masculin et du féminin dans notre langue que s'attaque l'auteure, historienne de la langue, dans cet ouvrage. On y découvre que la masculinisation de la langue française a été une entreprise de longue haleine, qui a suscité de vives résistances (pas seulement chez les femmes!), entre accords, pronoms, désignations des métiers, terminaisons féminines et autres processus dits grammaticaux, où s'est exprimée une misogynie sociale triomphante qui n'a pas dit son dernier mot. On y apprend que c'est avec les débuts de l'imprimerie que s'est posée peu à peu la question du genre des mots; que le mot «autrice»a été employé en 1570 sans poser de problèmes; ou que les rimes dites «féminines» et «masculines» des traités de poétique, relevaient par métonymie d'imaginaires qualités «douces» ou «dures» soi-disant attachées aux personnes ainsi désignées. Éliane Viennot démontre que la question «linguistique» fait, au long des siècles, écho à la question politique sur les femmes : de quoi sont-elles ou pas capables? faire le ménage? discourir? gouverner? Et que les familles royales et l'Église ne se sont pas privées de mettre leur grain de sel dans le débat. C'est ainsi que, dans la réflexion sur la langue, «la réalité sociale et politique interfèr(e) sans cesse dans des jugements apparemment techniques» (p. 43).

1. Voir aussi La France, les femmes et le pouvoir, éd. Perrin, 2006. 
Je vous laisse découvrir son parcours, sans en déflorer toutes les étapes, mais en soulignant quelques points de sa conclusion : à savoir que la langue française (p. 111) «n'est pas sexiste» mais genrée, et que cette partition en deux genres grammaticaux, quoi qu'on en dise et contrairement à d'autres langues, contrarie «les rêves des partisans de l'indifférence des sexes».

Cette riche «promenade» (p. 11) interroge, on s'en doute, notre école, nos enseignements et nos postures universitaires.

Marielle Rispail

CEDILEC, Université Jean Monnet - Saint-Étienne LIDILEM, Université Grenoble Alpes 